\title{
Congenital Fiber-Type Disproportion
}

National Cancer Institute

\section{Source}

National Cancer Institute. Congenital Fiber-Type Disproportion. NCI Thesaurus. Code C120046.

A rare genetic disorder caused by mutations in the TPM3, ACT A1, RYR1 and SEPN1 genes. It is inherited in an autosomal dominant or recessive pattern and rarely in an Xlinked pattern. It manifests with myopathy throug hout the body, particularly in the muscles of the shoulders, upper arms, hips, and thighs. Affected individuals may have contractures, lordosis, or scoliosis. In a minority of cases mild to severe breathing problems may occur. 